\title{
Acute Reduction in Spirometry Values After Prolonged Exercise Among Recreational Runners
}

\author{
Gerald S Zavorsky, Ralph D Zimmerman, Derek G Shendell, and Lynda T Goodfellow
}

\begin{abstract}
BACKGROUND: Prolonged endurance running may acutely reduce spirometric lung values. This study examined changes in spirometry before and immediately after prolonged endurance exercise (running and/or walking). Specifically, we examined potential factors that predict the presence of at least a $10 \%$ postexercise reduction in $\mathrm{FEV}_{1}$. METHODS: After institutional review board approval, recruitment occurred at a pre-race exposition, where informed consent was obtained. Pre-and post-race spirometry measurements were taken from 79 study subjects who competed in a half-marathon $(n=66)$ or a marathon $(n=13)$. Spirometry was performed 1-2 days before the marathon or half-marathon and 25 min after finish the race. RESULTS: We identified a subgroup of 23 subjects with a postexercise decrease in $\mathrm{FEV}_{1}$ of $\geq 10 \%$. In this subgroup, the mean post-race values for $\mathrm{FEV}_{1}$, FVC, and peak expiratory flow were 19-24\% lower than the pre-race values. In the 56 subjects with a change in $\mathrm{FEV}_{1}$ of $<10 \%$, the mean post-race changes in spirometry values were not $>6 \%$. There was no difference between the 2 groups in sex distribution or between subjects who completed the half-marathon or the full marathon. For every 1-y increase in age, the likelihood of developing a postexercise reduction in $\mathrm{FEV}_{1}$ of at least $10 \%$ decreased by nearly $10 \%$ $\left(\mathrm{R}^{2}=\mathbf{0 . 1 5}, P=.003\right)$. CONCLUSIONS: Exercise-induced bronchoconstriction (EIB) is the most probable explanation for the reduction in post-race $\mathrm{FEV}_{1}$. Prolonged endurance exercise reduced spirometric lung function by $\sim 20 \%$ in those with EIB. Age was the only predictor for EIB, and EIB did not affect the finish times among recreational runners and/or walkers. Key words: distance running; lung function; pulmonary; walking; exercise-induced bronchoconstriction; bronchospasm. [Respir Care 2019;64(1):26-33. (c) 2019 Daedalus Enterprises]
\end{abstract}

\section{Introduction}

Prolonged endurance running may acutely affect lung function in adults. After extended exercise (a marathon,

\footnotetext{
Drs Zavorsky, Zimmerman, and Goodfellow are affiliated with the Department of Respiratory Therapy, Georgia State University, Atlanta, Georgia. Dr. Shendell is affiliated with the Department of Environmental and Occupational Health, School of Public Health, Rutgers University, Piscataway, New Jersey, the New Jersey Safe Schools Program, School of Public Health, Rutgers University, Piscataway, New Jersey, and the Exposure Measurement and Assessment Division, Environmental and Occupational Health Sciences Institute, Rutgers Biomedical and Health Sciences, Piscataway, New Jersey.

Financial support provided by a Georgia State University Research Initiation grant and the Institute of Public Health at Georgia State University.
}

The authors have disclosed no conflicts of interest. ultra-marathon races [running], or triathlons that last several hours), pulmonary diffusing capacity, ${ }^{1-3} \mathrm{FEV}_{1},{ }^{4-6}$ FVC, ${ }^{1,4-13}$ and maximum inspiratory pressures and/or sustained inspiratory mouth pressures ${ }^{4,8,14,15}$ have been shown to be acutely reduced. Prolonged exercise could reduce $\mathrm{FEV}_{1}$ and FVC, particularly in cold weather, due to water loss from the epithelium, which leads to constriction of the airways, ${ }^{12}$ that is, exercise-induced bronchoconstriction (EIB). The FVC and $\mathrm{FEV}_{1}$ could also be reduced for other reasons: bronchial epithelial damage, ${ }^{16}$ environmental pol-

\footnotetext{
Presented as an abstract at the American College of Sports Medicine Annual Conference, in Minneapolis, Minnesota, May 29-June 2, 2018.

Correspondence: Gerald S Zavorsky, Department of Respiratory Therapy, Georgia State University, Urban Life Building, Room 1229, 140 Decatur Street SE, Atlanta, GA, 30302. E-mail: gerryzavorsky@gmail.com.
}

DOI: $10.4187 /$ respcare.05881 
lutants, ${ }^{17,18}$ allergies, respiratory muscle fatigue (as determined by a reduction in maximum voluntary ventilation or maximum inspiratory pressures ${ }^{4,5,8,14,15}$ ), and/or poor effort and/or poor technique. ${ }^{19}$ Pulmonary edema, which affects diffusing capacity, could also result from intense exercise..$^{1,20}$

Significant reductions in $\mathrm{FEV}_{1}$ or $\mathrm{FVC}$ have been shown to be unaltered after prolonged exercise due to either a small sample size (ie, $n=4)^{15}$ or a learning effect before and after exercise. The airways may also dilate from prolonged exercise, which causes an improvement in FVC. ${ }^{21,22}$ Another possibility is that there may be no actual acute change in lung function after prolonged exercise. 13,22

As such, the purpose of this study was 3-fold. First, we wanted to determine whether spirometric variables were altered due to prolonged exercise. Second, if there were significant changes in $\mathrm{FEV}_{1}$ before and after exercise, what were the predictive factors? Third, if the subjects demonstrated a reduction in postexercise $\mathrm{FEV}_{1}$ by at least $10 \%$, was it associated with endurance running performance? To answer these questions, we examined changes in spirometric lung function in a cohort of recreational joggers and walkers before and immediately after the 2008 ING (Internationale Nederlanden Groep) Georgia half-marathon and marathon.

\section{Methods}

This study was initially approved by the institutional review board of Georgia State University in 2007 (institutional review board H07344). In 2015, institutional review board permission was obtained to allow the lead author to work on the data for publication (institutional review board H16190).

Subjects were invited to take part in this study through recruitment at the marathon exposition 1-2 d before the event. Subjects were chosen based on their interest and willingness to take a short survey and sign a consent form. After voluntarily signing a consent form, anthropometric data were collected in a private area (ie, height and weight were measured). Then, by using a portable spirometer, Mir Spirolab III (Medical International Research, Rome, Italy), spirometry was performed with each participant by using the recommended guidelines published by the joint American Thoracic Society/European Respiratory Society task force ${ }^{23}$; then, 1-2 d later, the same individuals performed spirometry again immediately after the race according to these guidelines.

The interpretation of abnormal spirometric lung function was determined as any value below the lower limit of the normal range, that is, below the fifth percentile for age, sex, height, and ethnicity. ${ }^{24}$ The reference equations used to assess whether spirometry was normal for each subject was based on the Global Lung Function Initiative equa-

\section{QUICK LOOK}

\section{Current knowledge}

Acute changes in lung function triggered by exercise have been studied as early as the 1920s. Some studies indicate prolonged exercise reduces spirometric lung function, whereas other studies did not report such reduction.

\section{What this paper contributes to our knowledge}

Four percent of the study subjects had a mild obstructive pattern as defined by an $\mathrm{FEV}_{1}: \mathrm{FVC}$ below the lower limit normal pre-race. The decrease in $\mathrm{FEV}_{1}$ by at least $10 \%$ postexercise in $30 \%$ of the subjects was mostly representative of exercise-induced bronchoconstriction. The only predictor of exercise-induced bronchospasm was younger age. The presence or absence of exerciseinduced bronchospasm was not associated with time to completion of the half-marathon or marathon distance, which may be due to the lack of fast finishers in the sample.

tions for $\mathrm{FVC}, \mathrm{FEV}_{1}$, and $\mathrm{FEV}_{1}: \mathrm{FVC}^{.25}$ For peak expiratory flows, reference equations from Hankinson et $\mathrm{al}^{26}$ were used.

We identified a subgroup of subjects with a decrease in $\mathrm{FEV}_{1}$ of $\geq 10 \%$ within 30 -min post-race compared with pre-race based on the laboratory challenge test criterion for EIB, defined as a transient narrowing of the lower airway after exercise in the presence or absence of clinically recognized asthma. ${ }^{27,28}$ Specifically, a decrease in $\mathrm{FEV}_{1}$ of 10.0 to $24.9 \%$ was deemed mild EIB, a decrease in $\mathrm{FEV}_{1}$ between 25.0 and $49.9 \%$ was deemed moderate EIB, and a decrease in $\mathrm{FEV}_{1}$ of $\geq 50 \%$ was deemed severe EIB. ${ }^{28}$

\section{Statistical Analyses}

A 2-tailed independent $t$ test was used to examine mean differences in age, weight, height, and body mass index between the men and women, and for sex differences in spirometric function between the pre-race and the postrace. To examine the mean changes in spirometric function between the pre-race and the post-race, a 2-tailed paired $t$ test was used for the men and then separately again for the women. If any of the variables listed were not normally distributed, then a 2-tailed Wilcoxon signed-rank test was used to examine the mean changes or differences. As an added analysis, the pre-race percentages of predicted $\mathrm{FEV}_{1}, \mathrm{FVC}, \mathrm{FEV}_{1}: \mathrm{FVC}$, and peak expiratory flow were compared with the post-race values by using a paired 
Table 1. Baseline Measurements in the 79 Subjects Who Completed Both Pre- and Post-Race Testing

\begin{tabular}{lccc}
\hline \hline \multicolumn{1}{c}{ Measurement } & Men $(n=36)$ & Women $(n=43)$ & Total $(N=79)$ \\
\hline Age, mean \pm SD (range), y & $36 \pm 9(22-57)$ & $38 \pm 12(17-59)$ & $37 \pm 11(17-59)$ \\
Weight, mean \pm SD (range), kg & $79.4 \pm 10.2(58.7-101.6)$ & $63.4 \pm 12.3(47.0-99.4)^{*}$ & $70.8 \pm 11.5(47.0-101.6)$ \\
Height, mean \pm SD (range), cm & $177 \pm 8(155-191)$ & $164 \pm 7(152-178)^{*}$ & $170 \pm 10(152-191)$ \\
Body mass index, mean \pm SD (range), $\mathrm{kg} / \mathrm{m}^{2}$ & $25.3 \pm 3.3(20.8-36.7)$ & $23.4 \pm 3.9(17.4-36.2) *$ & $24.3 \pm 2.6(17.4-36.7)$
\end{tabular}

* Indicates a significant difference among the female subjects relative to the male subjects $(P<.05)$.

$t$ test. In this analysis, the percentage of predicted values controlled for age, height, sex, and ethnicity. As well, 2-tailed paired $t$ tests were used to compare the percentage of predicted spirometry values pre-race in subjects who completed the full study (pre- and post-race, group 1) with the subjects who only completed the pre-race spirometry (group 2). If any of the variables were not normally distributed, then the Mann-Whitney U test was used to compare the means between the groups.

Forward selection (conditional) binary logistic regression was conducted to determine which independent variables (the event distance, finish time, sex, age, and body mass index) were predictors of obtaining a postexercise reduction in $\mathrm{FEV}_{1}$ of at least $10 \%$ (yes or no) from exercise. Furthermore, a stepwise multiple linear regression was used to determine which factors were associated with finish times. The event distance, sex, age, and body mass index, and whether the subjects had a postexercise reduction in $\mathrm{FEV}_{1}$ by at least $10 \%$ or not (ie, EIB) were used as potential predictors in the model.

The sample size was calculated based on the change in $\mathrm{FEV}_{1}$ pre- and post-marathon from Maron et al. ${ }^{7}$ Between pre- and post-marathon, based on a $110-\mathrm{mL}$ reduction in $\mathrm{FEV}_{1}{ }^{7}$ and a correlation of 0.5 in $\mathrm{FEV}_{1}$, the effect size was calculated to be 0.54 ( $\mathrm{G}^{*}$ Power 3.1.9.2, Universität, Kiel, Germany). With an alpha error probability of .05 and a statistical power set at .80 , at least 30 subjects would be needed ( $t$ test family, the difference between 2 dependent means, G*Power 3.1.9.2).

\section{Results}

During the race on March 30, 2008, it was rainy and cool; the mean temperature was $47^{\circ} \mathrm{F}\left(8^{\circ} \mathrm{C}\right.$ [range, $6-10^{\circ} \mathrm{C}$ $\left.43-50^{\circ} \mathrm{F}\right]$ ), the mean relative humidity was $88 \%$ (range, $76-100 \%)$, and the dew point was $41^{\circ} \mathrm{F}\left(5^{\circ} \mathrm{C}\right)$. Overall, 2,226 runners and walkers finished the marathon, and 8,646 runners and walkers completed the half-marathon. A total of 294 participants signed a consent form and completed pre-race spirometry, but only 79 completed both pre-test and post-test spirometry to constitute the subjects for this study (group 1). The anthropometric characteristics of these recreational 79 runners are presented in Table 1.
Table 2. Comparison of Spirometric Values Pre-Race in the 79 Subjects Who Completed Both Pre- and Post-Race Testing (Group 1) With the 215 Subjects Who Only Completed Pre-Race Testing (Group 2)

\begin{tabular}{lccc}
\hline \hline \multicolumn{1}{c}{ Characteristic } & $\begin{array}{c}\text { Group 1 } \\
(n=79)\end{array}$ & $\begin{array}{c}\text { Group 2 } \\
(n=215)\end{array}$ & $\begin{array}{c}P, \\
\text { 2-tailed }\end{array}$ \\
\hline Age, mean $\pm \mathrm{SD}, \mathrm{y}$ & $37 \pm 11$ & $40 \pm 12$ & \\
Men, \% & 46 & 52 & \\
$\mathrm{FEV}_{1}$, mean $\pm \mathrm{SD}, \%$ predicted & $97 \pm 17$ & $92 \pm 17$ & .07 \\
$\mathrm{FVC}_{\text {, mean }} \pm \mathrm{SD}, \%$ predicted & $96 \pm 17$ & $92 \pm 16$ & .10 \\
$\mathrm{FEV}_{1}: \mathrm{FVC}$, mean $\pm \mathrm{SD}$, & $101 \pm 7$ & $100 \pm 9$ & .39 \\
$\quad \%$ predicted & & &
\end{tabular}

Because the data were not normally distributed, a Mann-Whitney U test was used to compare the different groups.

There were no differences in the pre-race percentages of predicted spirometry values between the 79 study subjects who completed both pre- and post-race testing (group 1) and the 215 participants who only completed pre-race testing (group 2) (Table 2). Based on the Global Lung Function Initiative reference equations, ${ }^{25} 3$ recreational runners (4\%) in group 1 who had complete pre- and post-race spirometry data displayed mild obstruction with the prerace $\mathrm{FEV}_{1}: \mathrm{FVC}$ being below the lower limit of a normal range, and the $\mathrm{FEV}_{1}$ of $>70 \%$ predicted. The subjects in group 2 showed a similar pattern.

The proportion of female and male finishers in this study compared with the total number of finishers in the halfmarathon (44\% men and 56\% women) and in the full marathon (66\% men and $34 \%$ women) was similar. We were not able to make a comparison of the age distribution between the marathon finishers in this study $(n=13)$ and the total number of finishers in the marathon $(2,226)$ due to an insufficient sample size. Of the 79 finishers who completed the full study (group 1), $73 \%$ were white (92\%), 3 were Asian (4\%), and 3 were African-American (4\%). Sixty-six study subjects finished the half-marathon: 27 men, with times that ranged from 92.3 to $209.2 \mathrm{~min}$ (mean \pm SD, $131.3 \pm 26.0 \mathrm{~min}$ ); and 39 women, with times that ranged from 103.1 to $231.5 \mathrm{~min}$ (mean $\pm \mathrm{SD}, 145.9 \pm 29.8 \mathrm{~min}$ ).

Nine men and 4 women finished the full marathon, with times that ranged from 210.8 to 256.3 min (mean \pm SD, 
Table 3. Pre- and Post-Race Spirometry Values Subdivided by Decreases in $\Delta \mathrm{FEV}_{1}<10 \%$ and $\geq 10 \%$

\begin{tabular}{|c|c|c|c|c|}
\hline Spirometry Value & $\begin{array}{l}\text { Pre-Race, } \\
\text { mean } \pm \text { SD }\end{array}$ & $\begin{array}{l}\text { Post-Race, } \\
\text { mean } \pm \text { SD }\end{array}$ & $\begin{array}{l}\text { Change, Post-Race - Pre-Race, } \\
\text { mean } \pm \text { SD (bootstrapped 95\% CI) }\end{array}$ & Change, $\%$ \\
\hline \multicolumn{5}{|c|}{$\Delta \mathrm{FEV}_{1}<10 \%(n=56)^{* \dagger}$} \\
\hline $\mathrm{FEV}_{1}, \mathrm{~L}$ & $3.28 \pm 0.76$ & $3.18 \pm 0.76$ & $-0.10 \pm 0.16(-0.14$ to -0.06$) \ddagger$ & -3 \\
\hline FVC, L & $3.96 \pm 0.95$ & $3.74 \pm 0.94$ & $-0.22 \pm 0.30(-0.31$ to -0.14$) \ddagger$ & -6 \\
\hline $\mathrm{FEV}_{1}: \mathrm{FVC}$ & $0.83 \pm 0.05$ & $0.85 \pm 0.07$ & $+0.02 \pm 0.05(0.01-0.04) \ddagger$ & +2 \\
\hline $\mathrm{PEF}, \mathrm{L} / \mathrm{s}$ & $6.90 \pm 2.23$ & $6.77 \pm 2.19$ & $-0.13 \pm 1.34(-6.49$ to 0.21$)$ & -2 \\
\hline \multicolumn{5}{|c|}{$\Delta \mathrm{FEV}_{1} \geq 10 \%(n=23) \S \|$} \\
\hline $\mathrm{FEV}_{1}, \mathrm{~L}$ & $4.05 \pm 1.02$ & $3.07 \pm 0.68$ & $-0.97 \pm 0.57(-1.20$ to -0.75$) \ddagger$ & -24 \\
\hline FVC, L & $4.89 \pm 1.31$ & $3.82 \pm 0.93$ & $-1.07 \pm 0.87(-1.43$ to -0.73$) \ddagger$ & -22 \\
\hline $\mathrm{FEV}_{1}: \mathrm{FVC}$ & $0.83 \pm 0.05$ & $0.81 \pm 0.09$ & $-0.02 \pm 0.08(-0.05$ to 0.01$)$ & -2 \\
\hline $\mathrm{PEF}, \mathrm{L} / \mathrm{s}$ & $8.16 \pm 3.03$ & $6.61 \pm 2.12$ & $-1.55 \pm 1.94(-2.36$ to -0.01$) \ddagger$ & -19 \\
\hline \multicolumn{5}{|c|}{ 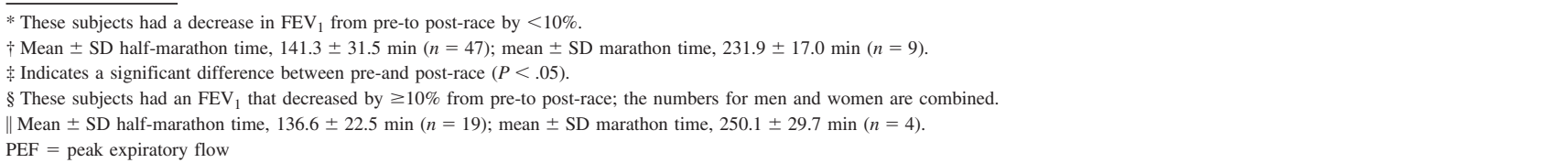 } \\
\hline
\end{tabular}

$232.4 \pm 16.6 \mathrm{~min}$ ), and from 220.3 to 288.9 min (mean \pm $\mathrm{SD}, 248.8 \pm 31.2 \mathrm{~min}$ ), respectively. Based on a walk-torun transition at $\sim 128 \mathrm{~m} / \mathrm{min}(7.7 \mathrm{~km} / \mathrm{h}$ or $4.8 \mathrm{miles} / \mathrm{h}),{ }^{29}$ 12 individuals (18\%) in this study predominantly walked the half-marathon. None of the 13 marathon finishers averaged a walking pace. Seventy-six study subjects were classified as "slow" finishers because the ratio of the sex and age-matched world record time for the event divided by their finish time was $<0.60$, whereas the other 3 subjects were classified as "local class" runners (0.60:0.69). ${ }^{30,31}$

There were differences in spirometric lung function between pre- and post-race. Spirometry was measured $25 \pm$ 7 min post-race, and there were differences compared with pre-race values. There were parallel reductions in $\mathrm{FEV}_{1}$ and FVC from pre- to post-race by $\geq 10 \%$ ( $\mathrm{r}=0.88$, $P<.001$ ). The peak expiratory flow decreased by $\sim 8 \%$ in $\sim 30 \%$ of the subjects (23/79), with no change in $\mathrm{FEV}_{1}: \mathrm{FVC}$. Men and women had similar changes in spirometric parameters from pre- to post-race. There was no difference in the proportion of men versus women, with a drop in $\mathrm{FEV}_{1}$ by $\geq 10 \%$ post-race (men, 12 of 36 subjects [33\%]; women, 11 of 43 subjects [26\%]; a difference of $7 \%$, chi-square test $=0.46, P=.50$ ). Twenty-three subjects ( $32 \pm 8 \mathrm{y}$ old) had a post-race $\mathrm{FEV}_{1}$ change that met a widely used criterion for EIB, and, of these, 7 men and 4 women had a postexercise change of $\geq 25 \%$, which would be considered moderate EIB. However, when these 23 subjects were compared with a subgroup of individuals with a postexercise $\mathrm{FEV}_{1}$ that changed by $<10 \%(n=56$; $40 \pm 11 \mathrm{y}$ of age), significant differences in the changes in spirometric function were observed (Table 3). In the subgroup without a post-race decrease in $\mathrm{FEV}_{1}$ by at least $10 \%$, the mean changes in spirometric parameters varied by no more than $6 \%$. In the subgroup with a post-race change in $\mathrm{FEV}_{1}$ by at least $10 \%$, there were decreases in $\mathrm{FEV}_{1}, \mathrm{FVC}$, and peak expiratory flow by $\sim 20 \%$.

To control for age, height, sex, and ethnicity, the percent of predicted values were compared between the preand post-race and were stratified by subgroups (Table 4). This finding indicated that there were no clinically meaningful changes (even though there were statistically significant changes) in the percent of predicted $\mathrm{FEV}_{1}, \mathrm{FVC}$, and $\mathrm{FEV}_{1}: \mathrm{FVC}$ between pre-and post-race in the subgroup of individuals with a postexercise decrease in $\mathrm{FEV}_{1}$ by $<10 \%$. The mean percent of predicted change in any spirometric variable was only as high as $5 \%$. However, in the subgroup of individuals with a postexercise change in $\mathrm{FEV}_{1}$ by at least $10 \%$, there was a mean decrease in the percent of predicted $\mathrm{FEV}_{1}$ and $\mathrm{FVC}$, and the peak expiratory flow by 18 to $26 \%$ (Table 4 ).

Binary logistic regression analysis $(n=79)$ indicated that age was the best predictor of a likelihood of obtaining a decrease in $\mathrm{FEV}_{1}$ of $\geq 10 \%$ postexercise. The model indicated that, for every 1-y increase in age, the likelihood of having a postexercise decrease in $\mathrm{FEV}_{1}$ by $10 \%$ or more was reduced by $7 \%(95 \%$ CI $2-12 \%,-2 \log$ likelihood $=86.7$, Nagelkerke $\mathrm{R}^{2}=0.15, P=.003$ ). The event distance, sex, finish time, and body mass index did not significantly add to the model, so these were not included in the final model.

Multiple linear regression analysis $(n=78)$ indicated that the distance run, age, body mass index, and sex predicted time to completion. Approximately $65 \%$ of the variance in the model was accounted for by the distance of the race (event), whereas age, body mass index, and sex accounted for 7, 5, and 5\% of the model, respectively (total adjusted $\mathrm{R}^{2}=0.82, P<.001$ ). Whether the 
Table 4. Pre- and Post-Race Percent Predicted Spirometry Values Subdivided by Decreases in $\Delta \mathrm{FEV}_{1}<10 \%$ or $\geq 10 \%$

\begin{tabular}{|c|c|c|c|}
\hline Spirometry Value & Pre-Race, mean \pm SD & Post-Race, mean \pm SD & $\begin{array}{c}\text { Change, Post-Race - Pre-race } \\
\text { (bootstrapped } 95 \% \mathrm{CI} \text { )* }\end{array}$ \\
\hline \multicolumn{4}{|l|}{$\Delta \mathrm{FEV}_{1}<10 \%(n=56) \dagger+$} \\
\hline $\mathrm{FEV}_{1}, \%$ predicted & $92 \pm 12$ & $90 \pm 12$ & $-3(-4$ to -2$) \S$ \\
\hline FVC, \% predicted & $91 \pm 11$ & $86 \pm 14$ & $-5(-7$ to -3$) \S$ \\
\hline $\mathrm{FEV}_{1}: \mathrm{FVC}, \%$ predicted & $101 \pm 7$ & $104 \pm 9$ & $+3(1-4) \S$ \\
\hline PEF, \% predicted & $83 \pm 23$ & $82 \pm 20$ & $-2(-7$ to 4$)$ \\
\hline \multicolumn{4}{|l|}{$\Delta \mathrm{FEV}_{1} \geq 10 \%(n=23) \| \mathbb{I}$} \\
\hline $\mathrm{FEV}_{1}, \%$ predicted & $109 \pm 21$ & $83 \pm 15$ & $-26(-32$ to -20$) \S$ \\
\hline FVC, $\%$ predicted & $109 \pm 22$ & $85 \pm 17$ & $-24(-31$ to -16$) \S$ \\
\hline $\mathrm{FEV}_{1}: \mathrm{FVC}, \%$ predicted & $100 \pm 6$ & $97 \pm 11$ & $-2(-6$ to 1$)$ \\
\hline PEF, \% predicted & $95 \pm 28$ & $78 \pm 25$ & $-18(-24$ to -11$) \S$ \\
\hline \multicolumn{4}{|c|}{$\begin{array}{l}\text { * Numbers are rounded for simplicity. } \\
\dagger \text { These subjects had a decrease in } \mathrm{FEV}_{1} \text { from pre-to post-race by }<10 \% \text {. } \\
¥ \text { Mean } \pm \text { half-marathon time, } 141.3 \pm 31.5 \mathrm{~min}(n=47) \text {; mean } \pm \text { marathon time, } 231.9 \pm 17.0 \min (n=9) \text {. } \\
\text { § Indicates a significant difference between pre- and post-race }(P<.05) \text {. } \\
\| \text { These subjects had an } \mathrm{FEV}_{1} \text { that decreased by } \geq 10 \% \text { from pre-to post-race. } \\
\text { II Mean } \pm \text { half-marathon time, } 136.6 \pm 22.5 \min (n=19) \text {; mean } \pm \text { marathon time, } 250.1 \pm 29.7 \min (n=4) \text {. } \\
\text { PEF = peak expiratory flow }\end{array}$} \\
\hline
\end{tabular}

subjects had a postexercise decrease in $\mathrm{FEV}_{1}$ of $\geq 10 \%$ did not affect the model, so this was omitted. The model was as follows:

Finish time $(\mathrm{min})=106.9 \times($ event $)+0.86 \times($ age in years) $+3.6 \times$ (body mass index in $\left.\mathrm{kg} / \mathrm{m}^{2}\right)+22.86 \times$ (sex) +5.3 ; adjusted $\mathrm{R}^{2}=0.82$, standard error of the estimate $(\mathrm{SEE})=19.8 \mathrm{~min}, P<.001$, in which, for sex, $0=$ male, 1 = female; and for the event, $0=$ half-marathon, $1=$ marathon; $n=78$. The standardized residual for one participant exceeded 3.0 SD units, and, thus, this participant was removed from the final model, which left 78 subjects in the model.

Because adding the event distance (marathon or halfmarathon) may dilute the contribution of other, more interesting factors, another multiple linear regression was performed on just the half-marathon subjects. Approximately $50 \%$ of this model was accounted for by body mass index (22\%), sex (19\%), and age (11\%), not whether the subjects had a postexercise decrease in $\mathrm{FEV}_{1}$ of $\geq 10 \%$. The model was as follows:

Half-marathon finish time $(\min )=3.65 \times$ (body mass index in $\left.\mathrm{kg} / \mathrm{m}^{2}\right)+20.83 \times(\mathrm{sex})+0.86 \times($ age in years $)+5.19$; adjusted $\mathrm{R}^{2}=0.49$, standard error of the estimate $(\mathrm{SEE})=20.0 \mathrm{~min},<.001$, in which, for sex, $0=$ male, $1=$ female. The standardized residual for one participant exceeded 3.0 SD units and thus that participant was removed from the model, which left 65 subjects in the model.

\section{Discussion}

When considering the first research question of whether prolonged exercise affects spirometric variables, post-race spirometric function had only minor decrements in most subjects, but a subgroup of $29 \%$ (23/79) had a decrease in $\mathrm{FEV}_{1}$ of $\geq 10 \%$, which met a universal criterion for EIB. This subgroup showed a parallel reduction in the mean FVC along with $\mathrm{FEV}_{1}$, which can result from bronchoconstriction and associated small airway closure but could also reflect reduced inspired volume caused by weakness, fatigue, or reduced motivation.

Mild interstitial pulmonary edema triggered by exercise could also have caused parallel reductions in $\mathrm{FEV}_{1}$ and $\mathrm{FVC}$. Mild interstitial pulmonary edema triggered by marathon running exercise occurs in a majority of subjects ${ }^{1,20}$; however, severe pulmonary edema triggered by exercise is rare..$^{32}$ For pulmonary edema to occur, the exercise should be exhaustive and at near-maximum effort. ${ }^{33}$ As mentioned previously, nearly $20 \%$ of the subjects walked, and most subjects were slow finishers. It is unlikely that the present study subjects were of sufficient fitness to stress the pulmonary system to the extent that moderate-to-severe pulmonary edema would occur. Thus, pulmonary edema was unlikely.

Cold temperature can trigger a postexercise reduction in $\mathrm{FEV}_{1}$. Reductions in $\mathrm{FEV}_{1}$ due to cold air are from the reduced water content of the air, rather than the low temperature. ${ }^{34}$ The inhaled water content from the ambient conditions of the race was $15 \%$ lower than in an indoor exercise laboratory. (The race conditions were $47^{\circ} \mathrm{F}\left(8^{\circ} \mathrm{C}\right)$ and $\sim 88 \%$ humidity, thus the inhaled water content would be $\sim 6.2 \mathrm{~g}$ of water per $\mathrm{kg}$ of air [7.4 $\mathrm{g} / \mathrm{m}^{3}$ ], which is $15 \%$ lower than in an exercise laboratory, at $68^{\circ} \mathrm{F}\left(20^{\circ} \mathrm{C}\right)$ and $50 \%$ humidity $[7.3 \mathrm{~g} / \mathrm{kg}$ or 8.7 $\mathrm{g} / \mathrm{m}^{3}$ ] [https://www.lenntech.com/calculators/humidity/ relative-humidity.htm] Accessed June 12, 2018). There- 
fore, the ambient weather conditions on race day could have triggered EIB.

Poor effort or poor technique in performing spirometric maneuvers is also possible for the postexercise reduction in $\mathrm{FEV}_{1}$. A submaximum inhalation, early termination, and/or variable effort can decrease $\mathrm{FEV}_{1}$ and FVC. ${ }^{19}$ Other studies had mean reductions in $\mathrm{FEV}_{1}{ }^{5}$ and $\mathrm{FVC}^{5,7}$ as with this study. In this investigation, the highest spirometric value of 3 postexercise trials was recorded and supported in all cases by another blow within $150 \mathrm{~mL}$, and, although, weak effort cannot be discounted, the researchers did encourage the subjects to do their best during spirometry testing. Upper airways obstruction was unlikely because the $\mathrm{FEV}_{1^{-}}$ to-peak expiratory flow ratio, which is an indicator of that, ${ }^{35}$ was not increased between pre- and post-race.

Exercise-induced respiratory muscle fatigue is also a possibility for the reduction in $\mathrm{FEV}_{1}$. Respiratory muscle fatigue can be indirectly determined by a reduction in maximum voluntary ventilation or maximum inspiratory pressures, which have been shown to occur in studies by using prolonged running exercise..$^{4,5,8,14,15}$ Loke et al ${ }^{15}$ observed a $10 \%$ decrease in maximum voluntary ventilation and a $14 \%$ decrease in maximum inspiratory pressure measured $\sim 40 \mathrm{~min}$ after completing a marathon $(P<.05)$. FVC decreased by $140 \mathrm{~mL}$. However, it was not statistically significant due to the small sample size $(n=4)$. Ross et $\mathrm{al}^{8}$ observed a $15 \%$ decrease in maximum inspiratory pressure $(P<.01)$ and a $270-\mathrm{mL}$ decrease in $\mathrm{FVC}(P=.06)$ immediately after completing a treadmill marathon.

Thus, inspiratory muscle fatigue could prevent the subjects from achieving full lung inflation post-race, which results in a lower FVC. This study did not measure maximum voluntary ventilation or inspiratory or expiratory pressures, which limited our findings. Furthermore, the pulmonary system may not have been overtaxed enough to cause respiratory muscle fatigue because most of the subjects were truly slow finishers, with $20 \%$ of the subjects walking the course. Lower airway narrowing seems more likely in this case because, in the studies that demonstrated respiratory muscle fatigue from marathon running through reductions in maximum voluntary ventilation and peak inspiratory pressures, the running pace was $25 \%$ faster compared with the present study. ${ }^{8,15}$

With regard to the second research question of predictive factors for the decrease in $\mathrm{FEV}_{1}$ by $\geq 10 \%$ postexercise, only age was a significant predictor. For every 1-y increase in age, there was a $7 \%$ less likelihood of having $\mathrm{a} \geq 10 \%$ decrease in $\mathrm{FEV}_{1}$ postexercise. Why was age a predictive factor for the decline in $\mathrm{FEV}_{1}$ triggered by exercise? One reason could be that the younger individuals gave a greater effort that was not reflected in the finish time. Another reason is that younger individuals may have airways that are more inclined to bronchoconstrict from exercise. It could also be that individuals with airway hyperreactivity are more likely to give up running as they age. Neither finish time nor event distance predicted a decrease in $\mathrm{FEV}_{1}$ by $\geq 10 \%$ postexercise. The subjects in this study with faster finish times would have a higher likelihood of altering airway osmolality, which triggered EIB. Indeed, expired ventilation rates $(\mathrm{mL} / \mathrm{kg} / \mathrm{min})$ have been shown to be $\sim 20 \%$ higher in runners who ran the marathon in $3 \mathrm{~h}$ compared with those runners who completed the marathon in $4 \mathrm{~h} .{ }^{36}$ However, it is possible that the event distance and finish time were omitted from the model due to the lack of faster runners in both distances. The study subjects were also too homogenous with respect to finish time.

In terms of the third research question, the presence or absence of at least a $10 \%$ reduction in $\mathrm{FEV}_{1}$ did not predict the finish time, only the distance run, age, body mass index, and sex affected the finish time. When examining only half-marathon finish times, body mass index and sex were the best predictors of finish time; the presence or absence of a postexercise decrease in $\mathrm{FEV}_{1}$ of $\geq 10 \%$ was not. That the presence or absence of a postexercise decrease in $\mathrm{FEV}_{1}$ of $\geq 10 \%$ was not related to the finish time could be related to a lack of cardiovascular fitness or a lack of maximum effort given by some subjects. This is a known limitation of this study, a natural experiment. Thus, overall, the stress on the pulmonary system could be questionable in this specific cohort of subjects. Also, the subjects were relatively homogenous in terms of finish times. There were no fast subjects. For finish times to be a significant predictor of postexercise decrease in $\mathrm{FEV}_{1}$ of $\geq 10 \%$, a heterogenous sample of faster and slower subjects is required. In addition, musculoskeletal soreness (which was not recorded) could also limit the finish time and cause a lack of association between alterations in lung function and the race time.

There were 215 individuals who did not complete the post-test spirometry (group 2). Possible reasons for not completing the post-test include (1) the subjects were not interested in completing the study, (2) the subjects were not able to find the kiosk, or (3) the subjects were distracted by family and friends, and forgot to show up for post-race testing. Alternatively, runners with acute bronchospasm may have failed to finish or may have opted out of post-race testing; conversely, symptomatic runners may have been motivated to get a post-race spirometry. However, the pre-testing analyses demonstrated that the percent of predicted for $\mathrm{FEV}_{1}, \mathrm{FVC}$, and $\mathrm{FEV}_{1}$ :FVC in these 215 subjects (group 2) was similar to the 79 subjects who performed spirometry post-race (group 1).

\section{Conclusions}

This study examined spirometric lung function in 79 recreational runners and/or walkers before and after a half- 
marathon or a full marathon. This study demonstrated that prolonged endurance exercise similarly reduced spirometric lung function by $\sim 20 \%$ in a subgroup of men and women. Age was the only predictor of a postexercise decrease in $\mathrm{FEV}_{1}$, and the postexercise decrease in $\mathrm{FEV}_{1}$ did not affect half-marathon or marathon finish times. The decrease in $\mathrm{FEV}_{1}$ by at least $10 \%$ postexercise in $30 \%$ of the subjects is mostly representative of EIB or respiratory muscle fatigue, although the former seems more likely. Future studies are needed to examine half-marathon and marathon performances by using faster runners in dry, freezing temperatures, and in hotter, more humid environments.

\section{ACKNOWLEDGMENTS}

We thank the respiratory therapy students who volunteered their time to help set up the pulmonary function testing area and who assisted in recruiting and data collection. We also thank Meron Kidane, student secretary, who helped organize the data and who performed various fact-finding tasks for the co-authors. We also thank the Georgia State University Research Foundation and the Institute of Public Health at Georgia State University for their financial and logistical support through the 2008 Interdisciplinary Team Research Award and for in-kind support from the Georgia ING Marathon LLC.

The authors dedicate this manuscript to the memory of Dr David E. Martin.

\section{REFERENCES}

1. Zavorsky GS, Milne EN, Lavorini F, Rienzi JP, Cutrufello PT, Kumar SS, et al. Small changes in lung function in runners with marathon-induced interstitial lung edema. Physiol Rep 2014;2(6): pii e12056.

2. Manier G, Moinard J, Téchoueyres P, Varène N, Guénard H. Pulmonary diffusion limitation after prolonged strenuous exercise. Respir Physiol 1991;83(2):143-153.

3. Caillaud C, Serre-Cousiné O, Anselme F, Capdevilla X, Préfaut C. Computerized tomography and pulmonary diffusing capacity in highly trained athletes after performing a triathlon. J Appl Physiol 1995; 79(4):1226-1232.

4. Hill NS, Jacoby C, Farber HW. Effect of an endurance triathlon on pulmonary function. Med Sci Sports Exerc 1991;23(11):1260-1264.

5. Vernillo G, Rinaldo N, Giorgi A, Esposito F, Trabucchi P, Millet GP, Schena F. Changes in lung function during an extreme mountain ultramarathon. Scand J Med Sci Sports 2015;25(4):e374-380.

6. Mahler DA, Loke J. Pulmonary dysfunction in ultramarathon runners. Yale J Biol Med 1981;54(4):243-248.

7. Maron MB, Hamilton LH, Maksud MG. Alterations in pulmonary function consequent to competitive marathon running. Med Sci Sports 1979;11(3):244-249.

8. Ross E, Middleton N, Shave R, George K, Mcconnell A. Changes in respiratory muscle and lung function following marathon running in man. J Sports Sci 2008;26(12):1295-1301.

9. Gordon B, Levine SA, Wilmaers A. Observations on a group of marathon runners. Arch Intern Med 1924;333(4):425-434.

10. Hug O. Sportärztliche Beobachtungen vom II. Schweizerischen Marathonlauf 1928. Schweiz Med Wochenschr 1929;59:522-525.

11. Hug O. Sportärztliche Beobachtungen vom I. Schweizerischen Marathonlauf 1927, unter besonderer Beruecksichtigung des Verhaltens der Kreislauforgane und der Atmung. Schweiz Med Wochenschr 1928;58:453-561.
12. Mahler DA, Loke J. Lung function after marathon running at warm and cold ambient temperatures. Am Rev Respir Dis 1981;124(2): 154-157.

13. Farrell PA, Maron MB, Hamilton LH, Maksud MG, Foster C. Time course of lung volume changes during prolonged treadmill exercise. Med Sci Sports Exerc 1983;15(4):319-324.

14. Ker JA, Schultz CM. Respiratory muscle fatigue after an ultra-marathon measured as inspiratory task failure. Int J Sports Med 1996; 17(7):493-496.

15. Loke J, Mahler DA, Virgulto JA. Respiratory muscle fatigue after marathon running. J Appl Physiol Respir Environ Exerc Physiol 1982;52(4):821-824.

16. Chimenti L, Morici G, Paternò A, Santagata R, Bonanno A, Profita $\mathrm{M}$, et al. Bronchial epithelial damage after a half-marathon in nonasthmatic amateur runners. Am J Physiol Lung Cell Mol Physiol 2010;298(6):L857-L862.

17. Rundell KW. High levels of airborne ultrafine and fine particulate matter in indoor ice arenas. Inhal Toxicol 2003;15(3):237-250.

18. Rundell KW. Pulmonary function decay in women ice hockey players: is there a relationship to ice rink air quality? Inhal Toxicol 2004;16(3):117-123.

19. Spirometric quality assurance: Common errors and their impact on test results (publication no. 2012-116). Department of Health and Human Services: National Institute for Occupational Safety and Health; 2012.

20. Zavorsky GS, Milne EN, Lavorini F, Rienzi JP, Lavin KM, Straub AM, Pistolesi M. Interstitial lung edema triggered by marathon running. Respir Physiol Neurobiol 2014;190:137-141.

21. Miles DS, Doerr CE, Schonfeld SA, Sinks DE, Gotshall RW. Changes in pulmonary diffusing capacity and closing volume after running a marathon. Respir Physiol 1983;52(3):349-359.

22. Warren GL, Cureton KJ, Sparling PB. Does lung function limit performance in a 24-hour ultramarathon? Respir Physiol 1989;78(2): 253-263.

23. Miller MR, Hankinson J, Brusasco V, Burgos F, Casaburi R, Coates A, et al.; ATS/ERS Task Force. Standardisation of spirometry. Eur Respir J 2005;26(2):319-338.

24. Pellegrino R, Viegi G, Brusasco V, Crapo RO, Burgos F, Casaburi $\mathrm{R}$, et al. Interpretative strategies for lung function tests. Eur Respir J 2005;26(5):948-968.

25. Quanjer PH, Stanojevic S, Cole TJ, Baur X, Hall GL, Culver BH, et al.; ERS Global Lung Function Initiative. Multi-ethnic reference values for spirometry for the 3-95-yr age range: the global lung function 2012 equations. Eur Respir J 2012;40(6): 1324-1343.

26. Hankinson JL, Odencrantz JR, Fedan KB. Spirometric reference values from a sample of the general U.S. population. Am J Respir Crit Care Med 1999;159(1):179-187.

27. Weiler JM, Brannan JD, Randolph CC, Hallstrand TS, Parsons J, Silvers W, et al. Exercise-induced bronchoconstriction update-2016. J Allergy Clin Immunol 2016;138(5):1292-1295.e36.

28. Parsons JP, Hallstrand TS, Mastronarde JG, Kaminsky DA, Rundell KW, Hull JH, et al.; American Thoracic Society Subcommittee on Exercise-induced Bronchoconstriction. An official American Thoracic Society clinical practice guideline: exercise-induced bronchoconstriction. Am J Respir Crit Care Med 2013;187(9): 1016-1027.

29. Hansen EA, Kristensen LAR, Nielsen AM, Voigt M, Madeleine P. The role of stride frequency for walk-to-run transition in humans. Sci Rep 2017;7(1):2010.

30. USATF masters age grading (2015). http://www.usatfmasters.org/ fa_agegrading.htm. Accessed February 2, 2018. 
31. Jones A. Runner's World age grade calculator 2015. https://www. runnersworld.com/tools/age-grade-calculator. Accessed February 2, 2018.

32. McKechnie JK, Leary WP, Noakes TD, Kallmeyer JC, MacSearraigh ET, Olivier LR. Acute pulmonary oedema in two athletes during a 90-km running race. S Afr Med J 1979;56(7):261-265.

33. Zavorsky GS. Evidence of pulmonary oedema triggered by exercise in healthy humans and detected with various imaging techniques. Acta Physiol (Oxf) 2007;189(4):305-317.
34. Smoliga JM, Weiss P, Rundell KW. Exercise induced bronchoconstriction in adults: evidence based diagnosis and management. BMJ 2016;352:h6951.

35. Empey DW. Assessment of upper airways obstruction. Br Med J 1972;3(5825):503-505

36. Lavin KM, Straub AM, Uhranowsky KA, Smoliga JM, Zavorsky GS. Alveolar-membrane diffusing capacity limits performance in Boston marathon qualifiers. PLoS One 2012;7(9):e44513.

This article is approved for Continuing Respiratory Care Education credit. For information and to obtain your CRCE

(free to AARC members) visit 